\title{
PREVALENCE OF DIABETIC RETINOPATHY IN TYPE 2 DIABETES MELLITUS: AN OBSERVATIONAL STUDY IN SOUTHERN INDIA
}

\author{
SATISH NAYAK ${ }^{1}$, KARTHIK RAO ${ }^{2}$, NAVIN PATIL ${ }^{3 *}$, JAYAPRAKASH B $^{2}$, AMITA PRIYA D $^{3}$, BALAJI ${ }^{3}$, RAO NR $^{4}$, \\ SARTHAK SINGHAL ${ }^{5}$
}

${ }^{1}$ Department of Gastroenterology, Kasturba Medical College, Manipal University, Manipal, Karnataka, India. ${ }^{2}$ Department of Internal Medicine, Kasturba Medical College, Manipal University, Manipal, Karnataka, India. ${ }^{3}$ Department of Pharmacology, Kasturba Medical College, Manipal University, Manipal, Karnataka, India. ${ }^{4}$ Consultant Physician, Anugraha Medical Centre, Udupi, Karnataka, India. ${ }^{5}$ MBBS Student, Kasturba Medical College, Manipal University, Manipal, Karnataka, India. Email: navin903@gmail.com

Received: 11 April 2017, Revised and Accepted: 03 May 2017

ABSTRACT

Objectives: In India, 69.1 million are diabetics as of 2015 compared to 18 million in 1995. Pan India prevalence study in diabetics carried out at 194 centers by All India Ophthalmological Society reported the prevalence of diabetic retinopathy (DR) among diabetics as $21.8 \%$. DR is of two types, non-proliferative diabetic retinopathy (NPDR), and proliferative diabetic retinopathy (PDR). The severity of NPDR depends on microaneurysms, hemorrhages, cotton wool spots, and beading of veins and can progress to PDR. Inherit characteristic of PDR is neovascularization. The aim of this observational prevalence study is to study the prevalence of diabetic retinopathy in Type 2 diabetic patients attending diabetic clinic and to study the distribution of diabetic retinopathy with respect to age, sex, and duration of disease in a tertiary care hospital in southern India.

Methods: This is a retrospective observational study. Age above 20 years and patients diagnosed with Type 2 diabetes mellitus (DM) and examined by the ophthalmologist were included and others excluded. Data documented were analyzed using statistical software SPSS version 16.

Results: About $52.07 \%$ of patients with Type 2 DM for more than 10 years had diabetic retinopathy and $13.07 \%$ of patients with Type 2 DM for more than 5 years have diabetic retinopathy.

Conclusion: India being the diabetic capital of the world and DR being the most common cause for visual impairment and blindness and it becomes empirical to assess the factors for its rising prevalence, which will significantly contribute in reducing the progression of DR.

Keywords: Diabetes mellitus, Diabetic retinopathy, Diabetic maculopathy, Chronic hyperglycemia.

(C) 2017 The Authors. Published by Innovare Academic Sciences Pvt Ltd. This is an open access article under the CC BY license (http://creativecommons. org/licenses/by/4. 0/) DOI: http://dx.doi.org/10.22159/ajpcr.2017.v10i8.19088

\section{INTRODUCTION}

Diabetes mellitus (DM) has exemplified its presence globally. In India, 69.1 million are diabetics as of 2015 compared to 18 million in 1995 [1,2]. At this rate, crossing one billion as estimated by the International Diabetes Federation Association and World health organization seems obvious [1]. Pan India studies on the prevalence of Diabetic retinopathy (DR) are limited, few initial studies, such as The Chennai Urban Rural Epidemiology Study and Arvind comprehensive eye study in rural population, concluded the prevalence of DR as $17.8 \%$ and $10.8 \%$ in diabetics, respectively [3,4]. Pan India prevalence study in diabetics carried out at 194 centers by All India Ophthalmological Society (AIOS) reported the prevalence of DR among diabetics as $21.8 \%$ [5]. The prevalence of DR at the time of diagnosis of Type $2 \mathrm{DM}$ is 7.3 as observed in a study at a tertiary care hospital [6].

DR is a common microvascular complication, an important complication among adults and elderly. DR is of two types, nonproliferative diabetic retinopathy (NPDR) and proliferative diabetic retinopathy (PDR). Severity of NPDR depends on microaneurysms, hemorrhages, cotton wool spots, and beading of veins and can progress to PDR. Inherit characteristic of PDR is neovascularization. Its either PDR or diabetic maculopathy that is responsible for vision loss. Chronic hyperglycemia inflicts profoundly in development and progression of DR by stimulating multiple mechanisms such as polyol pathway, enzymatic glycation, protein kinase $\mathrm{C}$ activation, hemodynamic changes, and renin angiotensin aldosterone pathway [7] and Type $2 \mathrm{DM}$ accounts for more than $90 \%$ of the diabetic population worldwide [8].
The aim of this observational prevalence study is to study the prevalence of DR in Type 2 Diabetic patients attending diabetic clinic and to study the distribution of DR with respect to age, sex, and duration of disease in a tertiary care hospital in southern India.

\section{METHODS}

Study design

This is a retrospective observational study. Institutional ethical clearance was obtained.

Study duration

April 2010 till October 2010.

Sampling method

Information taken from previous studies.

\section{Inclusion criteria}

Age above 20 years. All patients diagnosed with Type 2 DM and were examined by the ophthalmologist.

Exclusion criteria

All patients diagnosed of Type 2 DM and did not undergo ophthalmologist examination.

Data were collected and documented from medical records of patients fulfilling the inclusion criteria. Findings of ophthalmology examination as recorded by ophthalmologist were also documented: 
1. No retinopathy

2. NPDR

3. Proliferative retinopathy

4. Diabetic maculopathy or complicated with vitreous hemorrhage or retinal detachment.

\section{Statistical analysis}

Data documented were analyzed using statistical software SPSS version 16.

\section{RESULTS}

In Toto, 356 medical records of patients visiting the specialty diabetic clinic were viewed. 63 were excluded as they did not undergo ophthalmology examination (Table 1 and Fig. 1) depict the prevalence of DR unadjusted to age and sex. Out of 293 patients, 74.5\% (219) of them had no DR, 7.5\% (22) have non-proliferative retinopathy, $13.5 \%$ (40) have proliferative retinopathy, and 4\% (12) have complicated retinopathy. Total 185 males had diabetes out of which, $74.5 \%$ (138) had no retinopathy, $7.0 \%$ (13) had non-proliferative retinopathy, $13.5 \%$ (25) had proliferative retinopathy, and 4.8\% (9) had complicated retinopathy and among 108 diabetic females, 75\% (81) had no DR, $8.33 \%$ (15) had proliferative DR, 13.8\% (9) had non-proliferative and $2.7 \%$ (3) had complicated retinopathy (Table 2 and Fig. 2). Among 12 patients with complicated DR, 7 of them had retinal detachment, 4 of them had severe maculopathy with blindness and 1 had vitreous hemorrhage.

Agewise distribution depicted in (Fig. 3), 111 diabetics were above 60 years, 107 diabetics were in between 50-60 years, and 75 diabetics were below 50 years duration of disease. Out of 293 patients, 112 had diabetes for more than 10 years and 130 patients had DM for more than 5 years. 59 and 17 patient out of 112 and 130 patients respectively had DR. Therefore, the $52.07 \%$ of patients with Type 2 DM for more than 10 years had DR and $13.07 \%$ of patients with Type 2 DM for more than 5 years have DR.

\section{DISCUSSION}

The prevalence of diabetes and DR is continuously increasing. According to studies done in South Indian urban population, the prevalence of DR ranges from $12 \%$ to $22.4 \%[6,9,10]$. The prevalence of DR among other Asian countries such as Singapore and Japan is less compared to India possibly due to protective factors in these population or shorter duration of disease [2]. According to this study, the overall prevalence of DR in this diabetic population is $25 \%$, which correlates with $23.8 \%$ and $22 \%$ prevalence of DR reported by National Urban Diabetic Society and AIOS DR eye screening study 2014 [5,11]. Here, the population was not defined on the basis of socioeconomic status;

Table 1: Prevalence of diabetic retinopathy in study population

\begin{tabular}{ll}
\hline $\begin{array}{l}\text { Ophthalmoscopy } \\
\text { examination }\end{array}$ & $\begin{array}{l}\text { Total number of diabetics } \\
\text { retinopathy }(\%)\end{array}$ \\
\hline No retinopathy & $219(74.8)$ \\
Non-proliferative retinopathy & $22(7.5)$ \\
Proliferative retinopathy & $40(13.7)$ \\
Complicated & $12(4)$ \\
\hline
\end{tabular}

Table 2: Gender wise distribution of diabetic retinopathy

\begin{tabular}{lll}
\hline Ophthalmoscopy examination & Male (\%) & Female (\%) \\
\hline No retinopathy & $138(74.5)$ & $81(75)$ \\
NPDR & $13(7.0)$ & $9(8.33)$ \\
PDR & $25(13.51)$ & $15(13.8)$ \\
Complicated & $9(4.8)$ & $3(2.7)$ \\
Total & 185 & 108 \\
\hline
\end{tabular}

NPDR: Non-proliferative diabetic retinopathy, PDR: Proliferative diabetic retinopathy therefore, the prevalence among urban and rural population cannot be determined. The prevalence of diabetes is more among the patients with age $>60$ years (38\%) compared to age between $50-60$ years and less than 50 years. From 40 to 80 years, the prevalence of DR increases, then tapers slightly probably due to decreased life expectancy due to diabetes and other comorbidities.

In this study, the prevalence of DR is more among male compared to females; the reason for preponderance of DR irrespective of severity in males is unknown but similar prevalence of DR more in males is observed in studies such as The Chennai urban rural study, Andhra Pradesh eye disease study, and the United Kingdom prospective diabetes study [2]. One reason could be as males are genetically predisposed to noncommunicable health disorders such as atherosclerosis, myocardial infarction, and cancer. The prevalence of DR was more among those who had diabetes for 10 years or more compared to those who had duration of diabetes for 5 years or less correlates with the AIOS study wherein of all the 6418 patients screened and it was observed those with more than 5 years of diabetes had 35\% prevalence compared to those who had diabetes less than 5 years and 6 months [5]. Duration of the diabetes is a significant predictor for the prevalence of DR, risk

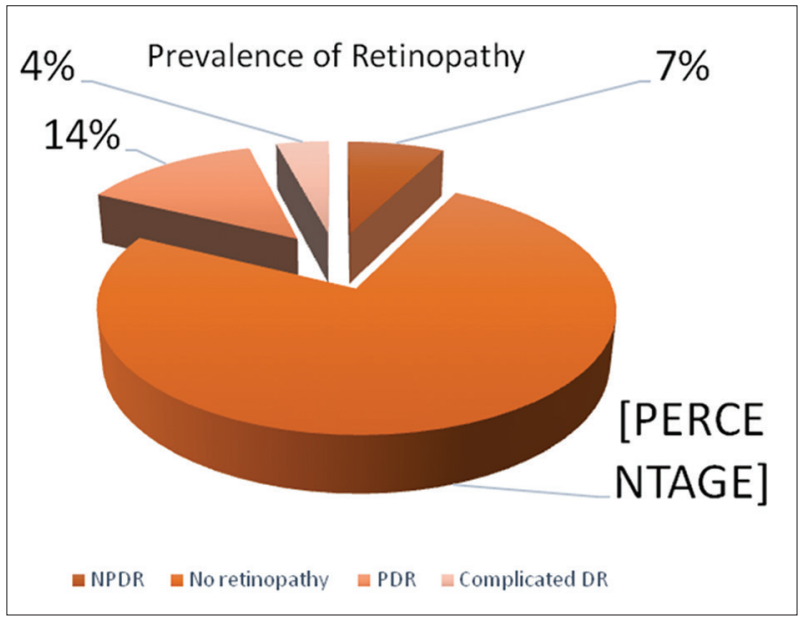

Fig. 1: Prevalence of retinopathy

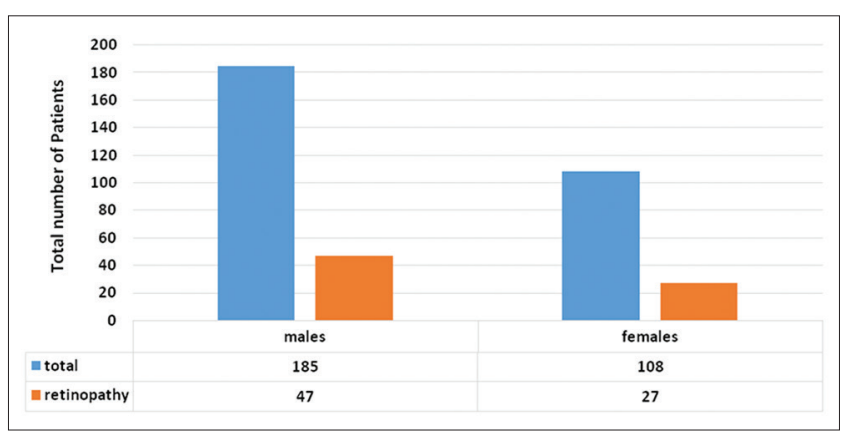

Fig. 2: Gender wise distribution of diabetic retinopathy

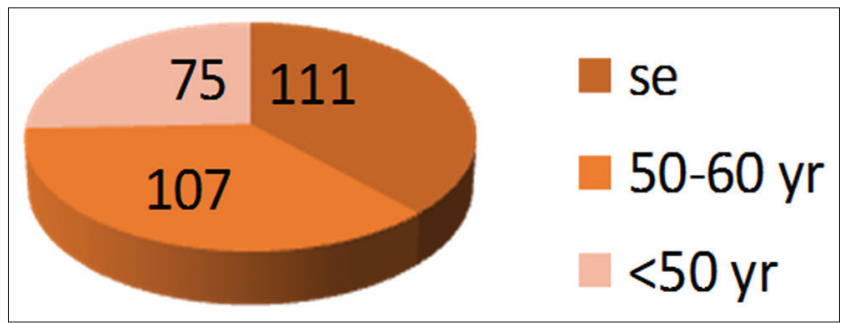

Fig. 3: Agewise distribution of diabetic patients 
increases with the increase in duration of disease. There are many risk factors that contribute to the development of retinopathy. The prevalence of diabetes and DR is less in rural population compared to urban, educated and affluent population as observed in one study carried out in rural population of Chennai [12]. The reason being reduced physical energy expenditure as a result of sedentary lifestyle and unhealthy dietary practices hence socioeconomic status plays a significant role in influencing the development of diabetes and its complications [12]. Furthermore, the lack of education, awareness or instructions regarding complications of diabetes or routine screening add to the burden of disease. The prevalence study among inpatients carried out by Jessica et al. it was observed that transportation, disability, affordability, no time, associated renal impairment, etc., were some of the factors along with age and duration of disease [13]. Limitations of this study were that the population were not further categorized as per socioeconomic status, education, comorbidities, etc., however the strength of this study is that reinforced the increasing prevalence of DR at a tertiary care hospital.

\section{CONCLUSION}

There are many prevalence studies in India signifying the prevalence of diabetes and DR among both urban and rural population and also risk factors that influence strongly the development of DR. Prevalence studies do have significance apart from providing health-care professionals a crucial information regarding the disease burden; they also implicate the challenges to be conquered in diagnosis, therapy, prognosis, and educating the patient. Screening and population-based studies in hospital setting can provide additional information on how factors like existing comorbidities influence DR. India being the diabetic capital of the world and DR being the most common cause for visual impairment and blindness; it becomes empirical to assess the factors for its rising prevalence, which will significantly contribute in reducing the progression of DR

\section{REFERENCES}

1. Raman R, Ganesan S, Pal SS, Kulothungan V, Sharma T. Prevalence and risk factors for diabetic retinopathy in rural India. Sankara
Nethralaya Diabetic Retinopathy Epidemiology and Molecular Genetic Study III (SN-DREAMS III), report no 2. BMJ Open Diabetes Res Care 2014;2(1):e000005.

2. Raman R, Rani PK, Reddi Rachepalle S, Gnanamoorthy P, Uthra S, Kumaramanickavel G, et al. Prevalence of diabetic retinopathy in India: Sankara Nethralaya Diabetic Retinopathy Epidemiology and Molecular Genetics Study report 2. Ophthalmology 2009;116(2):311-8.

3. Deepa M, Pradeepa R, Rema M, Mohan A, Deepa R, Shanthirani S, et al. The Chennai Urban Rural Epidemiology Study (CURES) - Study design and methodology (urban component) (CURES-I). J Assoc Physicians India 2003;51:863-70

4. Nirmalan PK, Katz J, Robin AL, Tielsch JM, Namperumalsamy P, $\mathrm{Kim} \mathrm{R}$, et al. Prevalence of vitreoretinal disorders in a rural population of southern India: The Aravind Comprehensive Eye Study. Arch Ophthalmol 2004;122(4):581-6.

5. Gadkari SS, Maskati QB, Nayak BK. Prevalence of diabetic retinopathy in India: The All India Ophthalmological Society diabetic retinopathy eye screening study 2014. Indian J Ophthalmol 2016;64(1):38-44.

6. Rema M, Deepa R, Mohan V. Prevalence of retinopathy at diagnosis among Type 2 diabetic patients attending a diabetic centre in South India. Br J Ophthalmol 2000;84(9):1058-60.

7. Tarr JM, Kaul K, Chopra M, Kohner EM, Chibber R. Pathophysiology of diabetic retinopathy. ISRN Ophthalmol 2013;2013:343560.

8. Jain R, Jain P, Jain P. A review on treatment and prevention of diabetes mellitus. Int J Curr Pharm Res 2016;8(3):16-8.

9. Dandona L, Dandona R, Naduvilath TJ, McCarty CA, Rao GN. Population based assessment of diabetic retinopathy in an urban population in southern India. Br J Ophthalmol 1999;83(8):937-40.

10. Ramachandran A, Snehalatha C, Vijay V, King H. Impact of poverty on the prevalence of diabetes and its complications in urban Southern India. Diabet Med 2002;19(2):130-5.

11. Ramachandran A, Snehalatha C, Kapur A, Vijay V, Mohan V, Das AK, et al. High prevalence of diabetes and impaired glucose tolerance in India: National Urban Diabetes Survey. Diabetologia 2001;44(9):1094-101.

12. Agarwal S, Raman R, Paul PG, Rani PK, Uthra S, Gayathree R, et al. Sankara Nethralaya-Diabetic Retinopathy Epidemiology and Molecular Genetic Study (SN-DREAMS 1): Study design and research methodology. Ophthalmic Epidemiol 2005;12(2):143-53.

13. Kovarik JJ, Eller AW, Willard LA, Ding J, Johnston JM, Waxman EL. Prevalence of undiagnosed diabetic retinopathy among inpatients with diabetes: The diabetic retinopathy inpatient study (DRIPS). BMJ Open Diabetes Res Care 2016;4(1):e000164. 